\title{
Effectiveness of endoscopic duodenal stenting for the management of patients with unresectable pancreatic
} cancer

Yusuke Niina ${ }^{1}$, Tetsuhide Ito ${ }^{1 *}$, Keijiro Ueda ${ }^{1}$, Lingaku Lee $^{1}$, Hisato Igarashi ${ }^{1}$, Masayuki Hijioka ${ }^{1}$, Takehiro Takaoka ${ }^{1}$, Takashi Fujiyama $^{1}$, Masami Miki ${ }^{1}$, Yuichi Tachibana ${ }^{1}$, Nao Fujimori ${ }^{1,2}$, Takao Ohtsuka ${ }^{3}$, Kazuhiko Nakamura ${ }^{1}$, Ken Kawabe ${ }^{1}$ and Yoshihiro Ogawa ${ }^{1}$

${ }^{1}$ Department of Medicine and Bioregulatory Science, Graduate School of Medical Sciences, Kyushu University, Fukuoka, Japan

${ }^{2}$ Department of Gastroenterology, Kyushu Medical Center, Fukuoka, Japan

${ }^{3}$ Department of Surgery and Oncology, Graduate School of Medical Sciences, Kyushu University, Fukuoka, Japan

\begin{abstract}
Background and aims: This study evaluated the effectiveness of endoscopic duodenal stenting (EDuS) for the treatment of unresectable pancreatic cancer.

Methods: The medical records of twenty patients with unresectable pancreatic cancer who underwent EDuS in a single institution were analyzed retrospectively.

Results: Both the technical and clinical success rates were $100 \%$. The median times of survival and stent patency were 113 and 109 days, respectively. In all patients, obstructive symptoms disappeared immediately after stenting. The mean time to resume oral intake after stenting was 1.8 days. The Gastric Outlet Obstruction Scoring System score was improved significantly after stenting. Fewer complications occurred in patients with obstruction in the horizontal part than in those with obstruction in other parts of the duodenum. Five patients lived $>6$ months after stenting without surgical treatment. Four of these patients had obstruction in the horizontal part, and they did not develop any complications after stenting.
\end{abstract}

Conclusion: EDuS for duodenal obstruction in patients with unresectable pancreatic cancer is an effective method. In particular, in patients with obstruction in the horizontal part, EDuS might contribute to long-term survival because of its association with fewer complications. Further studies are needed to clarify the indications for $\mathrm{EDuS}$.

\section{Introduction}

Gastric outlet obstruction (GOO) is a common complication of advanced distal gastric, duodenal, and periampullary malignancies including pancreatic cancer [1-3].

Pancreatic cancer, in particular, has a very high level of biological malignancy; it strongly tends to infiltrate into the surrounding organs including the duodenum. Duodenal obstruction caused by pancreatic cancer is reported to occur in $13-20 \%$ of patients with pancreatic cancer during the course of the disease [4]. Treatment of GOO associated with malignant disease is indicated because a poor clinical condition caused by nausea, vomiting, and malnutrition quickly develops in these patients. Surgical gastrojejunostomy has long been the standard palliative therapy for patients with malignant duodenal obstruction, but it is associated with considerable morbidity and even mortality $[5,6]$. In addition, bypass surgery requires $\geq 1$ week before oral intake becomes possible [7,8]. Recently, endoscopically placed self-expandable metallic stents have been increasingly used as a minimally invasive modality for the palliative treatment of malignant gastroduodenal obstruction [2,3]. A recent meta-analysis comparing endoscopic duodenal stenting (EDuS) and surgical treatment revealed the favorable efficacy of endoscopic treatment in terms of a shorter time for resuming oral intake after stenting and fewer complications [9]. However, most previous studies reported the efficacy of endoscopic treatment in relieving symptoms caused by gastrointestinal obstruction resulting from malignant diseases including pancreatic cancer as well as gastric cancer, gallbladder cancer, and cholangiocarcinoma. Few studies have specifically discussed the benefits of endoscopic treatment in pancreatic cancer, including a reduction of the time until the subsequent introduction or resumption of chemotherapy as well as its contribution to survival time. We therefore retrospectively investigated the palliative benefits of endoscopic stenting for duodenal obstruction associated with unresectable pancreatic cancer and the efficacy of endoscopic stenting in the treatment of pancreatic cancer in general, including its effects on patient tolerability to subsequent chemotherapy.

\section{Methods}

\section{Patients}

The medical records of 20 patients who underwent EDuS at Kyushu University Hospital were analyzed retrospectively. The clinical profiles of the patients are summarized in Table 1. The mean age of

Correspondence to: Dr. Tetsuhide Ito, $\mathrm{MD}, \mathrm{PhD}$, Department of Medicine and Bioregulatory Science, Graduate School of Medical Sciences, Kyushu University, 3-1-1 Maidashi, Higashi-ku, Fukuoka 812-8582, Japan; Tel: +81-92-642-5285, Fax: +81-92-642-5287; E-mail: itopapa@intmed3.med.kyushu-u.ac.jp

Key words: pancreatic cancer, duodenal obstruction, endoscopic duodenal stenting, self-expandable metallic stent

Received: January 08, 2017; Accepted: January 27, 2017; Published: January 30, 2017 
Table 1. Baseline characteristics of the patients.

\begin{tabular}{|l|l|}
\hline Number of patients & 20 \\
\hline Male:Female & $15: 5$ \\
\hline Age (mean \pm SD, years) & $66.4 \pm 10.8$ \\
\hline Histopathological diagnosis, no. & \\
\hline Adenocarcinoma, no. (\%) & $17(85)$ \\
\hline Pancreatic neuroendocrine tumor, no. (\%) & $2(10)$ \\
\hline Acinar cell carcinoma, no. (\%) & $1(5)$ \\
\hline Site of obstruction, no. (\%) & \\
\hline Bulbs & $2(10)$ \\
\hline Descending part & $4(20)$ \\
\hline Horizontal part & $14(70)$ \\
\hline GOOSS score (mean \pm SD) & $0.75 \pm 0.64$ \\
\hline ECOG PS (mean \pm SD) & $2.85 \pm 0.67$ \\
\hline
\end{tabular}

GOOSS, Gastric Outlet Obstruction Scoring System; ECOG PS,

Eastern Cooperative Oncology Group Performance Status; SD, standard deviation

Table 2. The Gastric Outlet Obstruction Scoring System.

\begin{tabular}{|l|c|}
\hline Oral intake & Score \\
\hline No oral intake & 0 \\
\hline Liquids only & 1 \\
\hline Soft solids & 2 \\
\hline Low-residue or full diet & 3 \\
\hline
\end{tabular}

the patients was $66.4 \pm 10.8$ years. There were fifteen men and five women, and all patients had unresectable International Union Against Cancer (UICC) stage IV pancreatic cancer. The ECOG PS was 2.85 \pm 0.67 . Due to the poor prognosis (within 6 months) and the poor general condition, all of patients could not undergo palliative surgery. They presented with symptoms related to gastroduodenal obstruction such as nausea, vomiting, and difficulty with oral intake. The extent of oral intake was evaluated using the Gastric Outlet Obstruction Scoring System (GOOSS) (Table 2) [10]. The GOOSS score before endoscopic treatment was $0.75 \pm 0.64$, and none of the patients could consume solid food. Duodenal obstruction was diagnosed with endoscopy and duodenography, 14 patients (70\%) in the horizontal part, 2 patients $(10 \%)$ in the bulbs, and 4 patients $(20 \%)$ in the descending part. In all patients, Histopathological evidence was obtained using one or more methods, such as endoscopic biopsy at the site of infiltration in the gastrointestinal tract, percutaneous ultrasound-guided tumor biopsy, cytology of the pancreatic juice or pancreatic duct brush specimens by endoscopic retrograde cholangiopancreatography (ERCP) and endoscopic ultrasonography (EUS)-guided fine needle aspiration. As a result, 17 patients had adenocarcinoma, 2 patients had pancreatic neuroendocrine tumors, and 1 patient had acinar cell carcinoma.

EDuS was performed after patients provided adequate written informed consent. The protocol of the present study was approved by the Clinical Study Ethical Review Board, Kyushu University.

\section{Stent placement}

In duodenal stenting, WallFlex ${ }^{\mathrm{TM}}$ duodenal stents $(22 \mathrm{~mm}$ in diameter: 60-120 mm in length; Boston Scientific Japan, Tokyo, Japan) were used. For the duodenal stenting, a side-viewing duodenoscope (TJF-260V; Olympus Medical Systems, Tokyo, Japan) was used.

First, the site of stenosis in the duodenum was identified endoscopically (Figure 1A), and a wire was placed at a position sufficiently distal from the stenosis site using a standard catheter (Tandem XL ${ }^{\mathrm{TM}}$; Boston Scientific Japan) for ERCP and a 0.035 -inch guide wire (Hydra Jag wire ${ }^{\mathrm{TM}}$; Boston Scientific Japan). Next, the image of the surrounding area of the stenosis site in the duodenum was obtained using a catheter, and the site of stenosis was confirmed under fluoroscopic guidance (Figure 1B-1C). After confirming the site and range of stenosis, a stent of appropriate length and the position of its placement were determined. Then, the duodenal stent was placed through the scope under fluoroscopic guidance while making minor adjustments to the position (Figure 1D-1F).

\section{Evaluation}

The patients who underwent EDuS via the aforementioned methods were analyzed retrospectively. Technical success, clinical success (whether oral intake could be resumed), the median time of stent patency, the median survival time from stenting, the mean time of resumption of oral intake after stenting, the extent of oral intake, whether chemotherapy could be performed after stenting, Eastern Cooperative Oncology Group (ECOG) Performance Status (PS), early complications (within 1 week after stenting), and late complications were examined. Duodenal reobstruction was defined as obstruction for which a treatment of any sort was required after stenting.

\section{Statistical analysis}

Wilcoxon's matched pairs test was used to compare the GOOSS score and ECOG PS of the patients before and after stenting. Fisher's test was used to compare the frequency of the occurrence of complications according to the site of stenosis. Survival time and stent patency were estimated using the Kaplan-Meier method. A P-value < 0.05 was considered statistically significant.

\section{Results}

\section{Clinical outcomes of the patients after stenting}

The clinical outcomes of the patients are shown in Table 3. EDuS was possible in all patients, and the symptoms of duodenal obstruction were resolved immediately after stenting. The median survival time after stent placement was 113 days. Six patients (30\%) survived for $>6$ months, with 1 patient, who remains alive, having survived for $>2$ years (Figure 2). The median time of stent patency was 109 days. Relapses of duodenal obstruction were observed in 5 patients (25\%). Among the cases of relapse, 3 cases were caused by stent kinking, but the conditions were improved after reintervention. No relapses of duodenal obstruction were observed during the course of the disease in other patients. By providing an appropriate reintervention, the symptoms of gastrointestinal obstruction could be controlled until
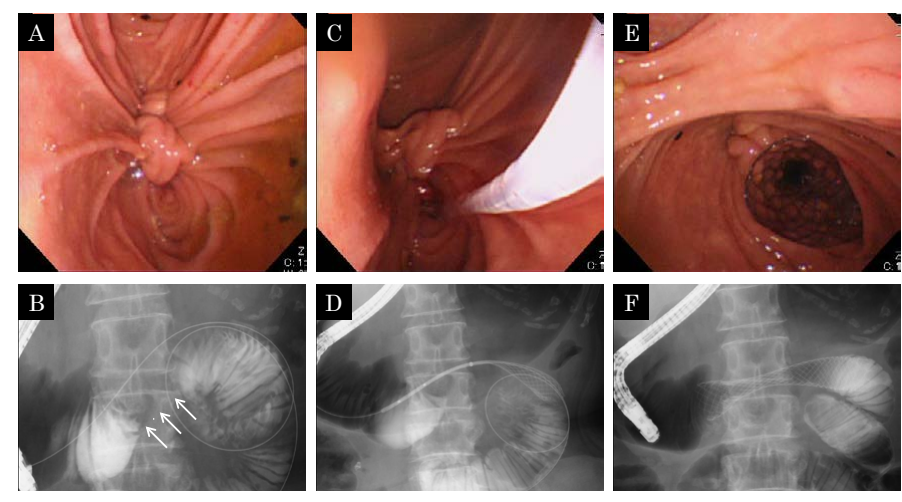

Figure 1. Duodenal metallic stent placement. (A) Duodenal obstruction was confirmed endoscopically. (B),(C) Contrast was injected into the duodenum through the catheter, and the range of duodenal obstruction (arrows) was assessed. (D) The metallic stent was placed through the scope under fluoroscopic guidance. (E) Endoscopic image of the proximal side of the stent in the duodenum. (F) Fluoroscopic image after stenting. 
death by endoscopic treatment alone in $90 \%$ of the patients. The median time necessary for the resumption of oral intake after stenting was 1.8 \pm 1.0 days. One patient could resume oral intake of liquid food alone, but other patients could resume oral intake of soft or solid food. When the GOOSS scores of the patients before and after stent placement were compared, the GOOSS scores after treatment were significantly improved (Figure $3 \mathrm{~A}$ ). The ECOG PS after treatment was $2.55 \pm 0.89$, indicating a tendency toward improvement (Figure 3B). Based on these results, 12 patients $(60 \%)$ were able to undergo chemotherapy after EDuS (Table 3).

Table 3. Main clinical outcomes of the patients after stent placement.

\begin{tabular}{|l|l|}
\hline Outcome & $\mathrm{n}=20$ \\
\hline Technical success, no. (\%) & $20(100)$ \\
\hline Clinical success, no. (\%) & $20(100)$ \\
\hline Median survival time in days after stent placement (range) & $113(32-$ not reached) \\
\hline Median number of days of stent patency (range) & $109(32-$ not reached) \\
\hline Mean number of days to resume oral ingestion (range) & $1.8(1-6)$ \\
\hline Persistent obstructive symptom, no. (\%) & $0(0)$ \\
\hline Recurrent obstructive symptom, no. (\%) & $5(25)$ \\
\hline Chemotherapy after stenting, no. (\%) & $12(60)$ \\
\hline Reinterventions, no. (\%) & $3(15)$ \\
\hline
\end{tabular}

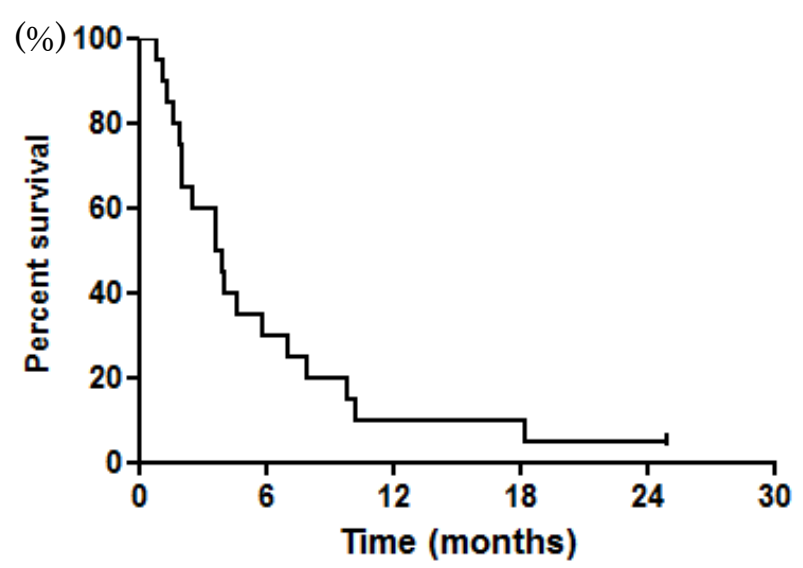

Figure 2. Kaplan-Meier curve of patient survival after stent placement. The median survival time after stenting was 113 days.

A

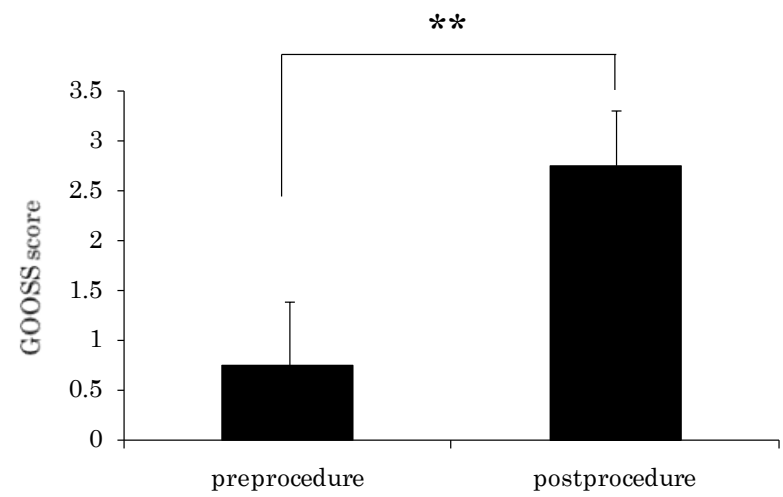

\section{Complications}

Complications that occurred during the study period are shown in Table 4. Overall, there were 8 cases of complications in 6 patients. Concerning early complications that occurred within 1 week after stenting, 1 patient experienced a temporary obstruction caused by residual food; however, this obstruction was resolved quickly after a short period of fasting. Similar complications were not observed after sufficient mastication was advised. Regarding late complications that occurred $>1$ week after the stent placement, 2 patients $(10 \%)$ developed cholangitis. In both these patients, stenosis developed in the descending part. A kink of the stent was observed in 3 patients (15\%), but the symptoms of duodenal obstruction improved immediately after adjusting the position of the stent using forceps. No relapses were observed until the death of these patients. Duodenal obstruction caused by tumor ingrowth was observed in 2 patients. One patient experienced a relapse 107 days after stenting and therefore, underwent surgical treatment. Another patient experienced a relapse of the obstructive symptoms 511 days after stenting, and the patient's general condition severely deteriorated. Therefore, the patient was placed under best supportive care. When the frequencies of occurrence of complications according to the site of obstruction were compared, the frequency in patients with obstruction in the horizontal part was significantly lower than that in patients with obstruction in other parts.

\section{The profiles of long-term surviving patients after stenting}

As shown in Figure 2 and 6 patients survived for $\geq 6$ months after EDuS. The details of the 6 patients are shown in Table 5. One patient developed duodenal obstruction because of tumor ingrowth and required surgery (Case No. 6). Regarding the 5 other patients, 4 patients had obstruction in the horizontal part, and they did not experience any

Table 4. Complications after stent placement.

\begin{tabular}{|l|l|l|}
\hline Complications & $\mathbf{n = 2 0}$ & \\
\hline Early complications & & \\
\hline temporary occlusion, no. (\%) & $1(5)$ & \\
\hline Late complications & & \\
\hline Cholangitis, no. (\%) & $2(10)$ & \\
\hline Stent kinking, no. (\%) & $3(15)$ & \\
\hline Tumor ingrowth, no (\%) & $2(10)$ & \\
\hline Total complications & 8 in 6 patients & P-value \\
\hline Site of obstruction & & $<0.01$ \\
\hline Horizontal part $v$ s. other parts, no. (\%) & $2(14)$ vs. $4(67)$ & \\
\hline
\end{tabular}

B

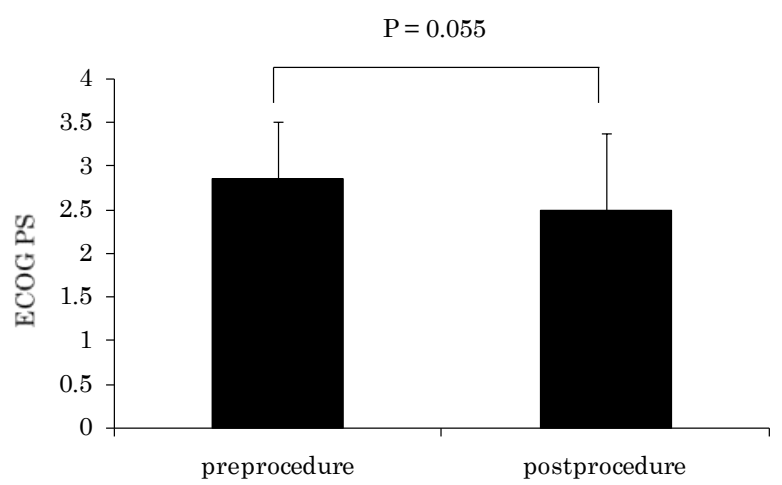

Figure 3.Comparison of GOOSS scores and the ECOG PS of the patients before and after stenting. (A) GOOSS score. (B) ECOG PS. Data are presented as the mean \pm SD. SD, standard deviation; GOOSS, Gastric Outlet Obstruction Scoring System; ECOG PS, Eastern Cooperative Oncology Group Performance Status; **, P $<0.01$. 
Table 5. Profiles of long-term surviving patients after stenting.

\begin{tabular}{|c|c|c|c|c|c|c|c|c|c|}
\hline Pt & Age & Sex & Diagnosis & $\begin{array}{c}\text { Site } \\
\text { of obstruction }\end{array}$ & $\begin{array}{c}\text { ECOG PS } \\
\text { pre-/post-stenting }\end{array}$ & $\begin{array}{c}\text { GOOSS score } \\
\text { pre-/post-stenting }\end{array}$ & $\begin{array}{l}\text { Survival after } \\
\text { stenting (days) }\end{array}$ & \begin{tabular}{|c|} 
Stent patency \\
(days)
\end{tabular} & Complication \\
\hline 1 & 57 & $\mathrm{M}$ & PDAC & HP & $3 / 2$ & $0 / 3$ & 236 & 236 & none \\
\hline 2 & 49 & $\mathrm{M}$ & PDAC & HP & $2 / 1$ & $1 / 3$ & 293 & 293 & none \\
\hline 3 & 86 & M & PDAC & HP & $3 / 2$ & $0 / 3$ & 211 & 211 & none \\
\hline 4 & 70 & $\mathrm{M}$ & PDAC & HP & $3 / 2$ & $1 / 3$ & NR (>2 years) & NR ( $>2$ years) & none \\
\hline 5 & 51 & $\mathrm{~F}$ & PDAC & DP & $3 / 2$ & $0 / 3$ & 546 & 511 & $\mathrm{C}, \mathrm{K}, \mathrm{TI}$ \\
\hline 6 & 60 & M & PDAC & DP & $3 / 2$ & $0 / 3$ & 306 & 107 & TI \\
\hline
\end{tabular}

PDAC, pancreatic ductal adenocarcinoma; HP, horizontal part; DP, descending part; ECOG PS, Eastern Cooperative Oncology Group Performance Status; NR, not reached; C, cholangitis; $\mathrm{K}$, kink of stent; TI, tumor ingrowth

major complications. All 5 patients could resume normal food intake, and their ECOG PS was improved to a level permitting the resumption of chemotherapy.

\section{Discussion}

We conducted a retrospective study to clarify the usefulness of EDuS in patients with unresectable pancreatic cancer in terms of symptomatic relief as well as the possibility of subsequent chemotherapy and its contribution to long-term survival.

In patients with unresectable pancreatic cancer, progression of the disease is occasionally accompanied by duodenal obstruction. These patients usually have limited prognoses with a low life expectancy and a poor quality of life (QOL) because of an inability to eat. Consequently, there are high incidences of poor nutritional status and dehydration. Previously, surgical bypass surgery was performed in these patients $[5,6]$. However, since Kozarek et al. reported the usefulness of duodenal stenting in 1922, EDuS has generally been conducted to alleviate the symptoms of duodenal stenosis associated with malignant diseases [11]. Studies comparing endoscopic stenting and surgical bypass have reported that although there were no obvious differences in efficacy and overall survival, the time until the resumption of oral ingestion was earlier and the duration of hospitalization was shorter in patients who underwent endoscopic stenting [7,12]. For these reasons, endoscopic stenting has been reported to be a feasible, safe, and effective alternative palliative treatment [13-15].

In our present study, the technical and clinical success rates were both $100 \%$. The GOOSS score was significantly improved after stent placement, and the efficacy of the treatment was comparable to or slightly better than previously reported results $[2,16,17]$. In addition, concerning early complications that occurred within 1 week after stenting, only 1 patient developed temporary obstruction because of residual food. This temporal obstruction was conservatively improved. The period from stenting to the resumption of oral intake was short (1.8 \pm 1.0 days), and by providing appropriate reinterventions, $90 \%$ of the patients could live without symptoms of gastrointestinal obstruction until death. Thus, endoscopic stenting is considered safe and effective, and it contributes to the improvement of QOL.

In this study, 8 complications occurred in 6 patients. Excluding the aforementioned early complications, stent kinking was observed in 3 patients, cholangitis was present in 2 patients, and tumor ingrowth was noted in 2 patients as the late complications that appeared $\geq 1$ week after stenting.

Firstly, stent kinking was found in 3 patients, each with stenosis in the bulbs, descending part, or horizontal part. The kinks were corrected immediately by endoscopic repositioning of the stents using forceps. Previous studies also reported that the placement of an additional stent or endoscopic repositioning produced relatively good results for the treatment of patients with kinks [18].

In the present study, 2 patients (10\%) repeatedly developed cholangitis, and both of them had stenosis in the descending duodenum. These 2 patients underwent metallic stent placement to treat both descending duodenum obstruction and biliary obstruction, but they repeatedly developed cholangitis after the placement of duodenal stents. Togawa et al. reported that the insertion of a new metallic stent should be considered as the treatment of choice for the management of dysfunctional biliary metallic stents [19]. However, a recent study reported that duodenal infiltration is a risk factor for the obstruction of biliary metal stents within 3 months [20]. Thus, the treatment of obstruction in the descending part in patients with carcinoma of the head of the pancreas, which often causes obstructions in both the duodenum and the bile duct, should be carefully considered; for example, bypass surgery may need to be considered.

Previous studies reported that the median survival times after the insertion of a duodenal stent in patients with malignant duodenal stenosis associated with pancreatic cancer or other types of cancers were $49-195$ days $[2,3,8,10,21]$. Studies limited to pancreaticobiliary cancer alone reported that the median survival times after stent placement were 69-119 days $[17,18,22]$. In our present study, the median survival time after stenting was 113 days, which was comparable to the results of previous studies. Among our patients, 6 patients (30\%) survived for $>6$ months after stent placement. One of these patients developed duodenal reobstruction because of tumor ingrowth and underwent surgery 107 days after endoscopic stent placement. When this patient initially presented with symptoms of duodenal obstruction, his/her nutritional and general conditions were poor; therefore, endoscopic treatment was chosen. Later, the patient's general conditions were improved, and standard chemotherapy became possible; however, reobstruction caused by tumor ingrowth occurred during the course of treatment. At that time, the patient's general condition was relatively stable, and thus, we performed bypass surgery with the goal of long-term, stable oral intake. After the bypass surgery, the patient survived for $>6$ months without experiencing relapses of the symptoms of gastrointestinal obstruction. In a previous study, gastrojejunostomy was reported to be superior in terms of long-term results compared to EDuS [23]. In our institution, some patients with relatively stable general conditions were chosen to undergo bypass surgery to treat duodenal obstruction, but we have encountered cases in which general conditions after surgery were not improved and the resumption of chemotherapy was impossible. Therefore, the choice between endoscopic and surgical treatment should be considered carefully.

On the contrary, 5 patients (25\%) survived $\geq 6$ months without surgical treatment, i.e., only with endoscopic treatment. The ECOG PS and GOOSS scores after treatment were improved in all the patients 
(Table 5), and postoperative chemotherapy could be resumed. In previous clinical studies, the median overall survival times after gemcitabine therapy, which has been considered the gold standard for unresectable pancreatic cancer, were reported to be 5.65-8.8 months [24-26]. Generally, duodenal obstruction is considered to occur at a very advanced stage [1-3], and survival for $>6$ months after treatment of duodenal obstruction is considered a good result. Among the 5 patients, 4 patients, including 1 patient who has survived for $>2$ years after stenting, had stenosis in the horizontal part. The ECOG PS of all 4 patientswaspoorduring endoscopictreatment; however, aftertreatment, the ECOG PS was improved to a level permitting the resumption of chemotherapy (Table 5). Interestingly, all 4 patients could consume normal food, and they had no complications for $>6$ months after stent placement. Because they had no complications, chemotherapy could be continued stably without interruption, and this may have led to the favorable outcomes. As described previously, patients with stenosis in the horizontal part had significantly fewer complications than those with stenosis in other areas (Table 4). In addition, considering the low invasiveness of the procedure and the short time to the resumption of oral intake after the intervention, endoscopic stenting is considered favorable for patients with obstruction in the horizontal part, in that long-term, stable chemotherapy, which contributes to a long survival time, becomes possible. However, considering that the number of patients in this study was small, further studies concerning which patients are better suited for endoscopic treatment will be necessary.

\section{Conclusion}

Endoscopic treatment is a safe and effective treatment for patients with duodenal obstruction associated with unresectable pancreatic cancer, and it contributes to the QOL of the patients. Patients with stenosis in the horizontal part in particular have significantly fewer complications after EDuS. This enables the stable continuation of chemotherapy, thereby contributing to a long survival time. However, the application of endoscopic treatment in these patients warrants further accumulation of clinical study data.

\section{References}

1. Dormsnn A, Meisner S, Verin N, Wenk Lang A (2004) Self-expanding metal stents for gastroduodenal malignancies: systematic review of their clinical effectiveness. Endoscopy 36: 543-555. [Crossref]

2. Kim JH, Song HY, Shin JH, Choi E, Kim TW,et al. (2007) Metallic stent placement in the palliative treatment of malignant gastroduodenal obstructions: prospective evaluation of results and factors influencing outcome in 213 patients. Gastrointest Endosc 66: 256-264. [Crossref]

3. vanHooft JE, Uitdehaag MJ, Bruno MJ, Timmer R, Siersema PD, et al. (2009) Efficacy and safety of the new WallFlex enteral stent in palliative treatment of malignant gastric outlet obstruction (DUOFLEX study): a prospective multicenter study. Gastrointest Endosc 69: 1059-1066. [Crossref]

4. Conio M, Demarquay JF, De Luca L, Marchi S, Dumas R (2001) Endoscopic treatment of pancreatico-biliary malignancies. Crit Rev Oncol Hematol 37: 127-135.[Crossref]

5. Del Piano M, Ballarè M, Montino F, Todesco A, Orsello M, et al. (2005) Endoscopy or surgery for malignant GI outlet obstruction?.Gastrointest Endosc 61: 421-426. [Crossref]

6. Siddiqui A, Spechler SJ, Huetra S (2007)Surgical bypass versus endoscopic stenting for malignant gastroduodenal obstruction: a decision analysis. Dig Dis Sci 52: 276-281. [Crossref]

7. Chandrasegaram MD, Eslick GD, Mansfield CO, Liem H, Richardson M,et al. (2012) Endoscopic stenting versus operative gastrojejunostomy for malignant gastric outlet

\section{obstruction. Surg Endosc 26: 32332-32339. [Crossref]}

8. Jeurnink SM, Polinder S, Steyerberg EW, Kuipers EJ, Siersema PD (2010) Cost comparison of gastrojejunostomy versus duodenal stent placement for malignant gastric outlet obstruction. J Gastroenterol 45: 537-543. [Crossref]

9. Hosono S, Ohtani H, Arimoto Y, Kanamiya Y (2007) Endoscopic stenting versus surgical gastroenterostomy for palliation of malignant gastroduodenal obstruction: a meta-analysis. J Gastroenterol 42: 283-290. [Crossref]

10. Adler DG, Baron TH (2002) Endoscopic palliation of malignant gastric outlet obstruction using self-expanding metal stents: Experience in 36 patients. $\mathrm{Am} \mathrm{J}$ Gastroenterol 97: 72-78. [Crossref]

11. Kozarek RA, Ball TJ, Patterson DJ (1992) Metallic self -expanding stent application in the upper gastrointestinal tract: Caveats and concerns. Gastrointest Endosc 38: 1-6. [Crossref]

12. Rudolph HU, Post S, Schlüter M, Seitz U, Soehendra N, Kähler G (2011) Malignant gastroduodenal obstruction: retrospective comparison of endoscopic and surgical palliative therapy. Scand J Gastroenterol 46: 583-590. [Crossref]

13. Mehta S, Hindmarsh A, Cheong E, Cockburn J, Saada J, et al. (2006) Prospective randomized trial of laparoscopic gastrojejunostomy versus duodenal stenting for malignant gastric outflow obstruction. Surg Endosc 20: 239-242. [Crossref]

14. Mosler P, Mergener KD, Brandabur JJ, Schembre DB, Kozarek RA (2005) Palliation of gastric outlet obstruction and proximal small bowel obstruction with self-expandable metal stents: a single center series. J Clin Gastroenterol 39: 124-128. [Crossref]

15. Bethge N, Breitkreutz C, Vakil N (1998) Metal stents for the palliation of inoperable upper gastrointestinal stenoses. Am J Gastroenterol 93: 643-645.[Crossref]

16. Cha BH, Lee SH, Kim JE, Yoo JY, Park YS, et al. (2013) Endoscopic self-expandable metallic stent placement in malignant pyloric or duodenal obstruction: Does chemotherapy affect stent patency? Asia Pac J Clin Oncol 9: 162-168. [Crossref]

17. Tonozuka R, Itoi T, Sofuni A, Itokawa F, Moriyasu F (2013) Endoscopic double stenting for the treatment of malignant biliary and duodenal obstruction due to pancreatic cancer. Dig Endosc25 Suppl 2: 100-108.[Crossref]

18. Woo SM, Kim DH, Lee WJ, Park KW, Park SJ, et al. (2013) Comparison of uncovered and covered stents for the treatment of malignant duodenal obstruction caused by pancreaticobiliary cancer. Surg Endosc 27: 2031-2039.[Crossref]

19. Togawa O, Isayama Y, Tsujino T, Nakai Y, Kogure H, et al. (2013) Management of dysfunctional covered self-expandable metallic stents in patients with malignant distal biliary obstruction. J Gastroenterol 48: 1300-1307. [Crossref]

20. Hamada T, Isayama H, Nakai Y, Togawa O, Kogure H, et al. (2011) Duodenal invasion is a risk factor for the early dysfunction of biliary metal stents in unresectable pancreatic cancer. Gastrointest Endosc. 74:548-555. [Crossref]

21. Maetani I, Isayama H, Mizumoto Y (2007) Palliation in patients with malignant gastric outlet obstruction with a newly designed enteral stent: a multicenter study. Gastrointest Endosc 66: 355-360. [Crossref]

22. Kim ID, Kang DH, Choi CW, Kim HW, Jung WJ, et al. (2010) Prevention of covered enteral stent migration in patients with malignant gastric outlet obstruction: A pilot study of anchoring with endoscopic clips. Scand J Gastroenterol 45: 100-105. [Crossref]

23. Jeurnink SM, Steyerberg EW, Hof Gv, van Ejick CH, Kuipers EJ, et al. (2007) Gastrojejunostomy versus stent placement in patients with malignant gastric outlet obstruction: A comparison in 95 patients. J Surg Oncol 96: 389-396. [Crossref]

24. Burris HA, Moore MJ, Andersen J, Green MR, Rothenberg ML, et al. (1997) Improvements in survival and clinical benefit with gemcitabine as first-line therapy for patients with advanced pancreas cancer: a randomized trial. J Clin Oncol 15: 24032413.[Crossref]

25. Moore MJ, Goldstein D, Hamm J, Figer A, Hecht JR, et al. (2007) Erlotinib plus gemcitabine compared with gemcitabine alone in patients with advanced pancreatic cancer: A phase III trial of the National Cancer Institute of Canada Clinical Trials Group. J Clin Oncol 25: 1960-1966. [Crossref]

26. Ueno H, Ioka T, Ikeda M, Ohkawa S, Yanagimoto H, et al. (2013) Randomized phase III study of gemcitabine plus S-1, S-1 alone, or gemcitabine alone in patients with locally advanced and metastatic pancreatic cancer in Japan and Taiwan: GEST study. $J$ Clin Oncol 31: 1640-1648. [Crossref]

Copyright: $(2017$ Niina Y. This is an open-access article distributed under the terms of the Creative Commons Attribution License, which permits unrestricted use, distribution, and reproduction in any medium, provided the original author and source are credited. 